\title{
Characterization of Bordetella Strains and Related Bacteria by Amplified Ribosomal DNA Restriction Analysis and Randomly and Repetitive Element-Primed PCR
}

\author{
P. VANDAMME, ${ }^{1,2 *}$ M. HEYNDRICKX, ${ }^{1}$ I. DE ROOSE ${ }^{1}$ C. LAMMENS, ${ }^{2}$ P. DE VOS, ${ }^{1}$ AND K. KERSTERS ${ }^{1}$ \\ Laboratorium voor Microbiologie, University of Ghent, Ghent, ${ }^{1}$ and Department of Medical Microbiology, University \\ Hospital ULA, Antwerp, ${ }^{2}$ Belgium
}

\begin{abstract}
Amplified ribosomal DNA restriction analysis (ARDRA) in which the almost complete 16S rRNA gene was used as the target of the PCR assay and randomly and repetitive element-primed PCR were used to characterize 67 strains belonging to the family Alcaligenaceae. Particular emphasis was placed on strains of Bordetella pertussis (13 strains), Bordetella parapertussis (10 strains), and Bordetella bronchiseptica (10 strains) (these organisms were referred to as the $B$. bronchiseptica group), as well as Bordetella avium (19 strains). Our data indicate that strains belonging to the $B$. bronchiseptica group behave as a single species comparable to strains of $B$. avium. ARDRA allowed us to differentiate among all other species as well but was not useful for infraspecific typing. Randomly and repetitive element-primed PCR could be used to distinguish several infraspecific types within $B$. avium and the $B$. bronchiseptica group and allowed us to differentiate these two taxa.
\end{abstract}

A multitude of DNA-based typing methods are gradually replacing or augmenting classical typing methods $(13,17)$. Most of these methods are based on specific or random amplification of DNA fragments, digestion of genomic or amplified DNA with restriction enzymes, or both. The majority of these methods were developed primarily to generate highly specific (if possible, strain-specific) fingerprints. Some, however, have proved to be useful for both species identification and strain characterization.

In the present study, we examined the discriminatory abilities of two of these genome-orientated methods for strains belonging to the family Alcaligenaceae, particularly Bordetella pertussis, Bordetella parapertussis, Bordetella bronchiseptica, and Bordetella avium strains. The population structure of $B$. pertussis, $B$. parapertussis, and $B$. bronchiseptica is considered clonal $(14,15)$, and the taxonomic status of these taxa has been the subject of debate, as they exhibit greater than $80 \%$ DNA-DNA binding despite considerable phenotypic and chemotaxonomic differences $(11,15,18,21,24)$. We selected about 10 strains of $B$. pertussis, $B$. parapertussis, and $B$. bronchiseptica and compared the results of genomic typing analyses with the results obtained for 19 B. avium strains. Reference strains of all other Bordetella and Alcaligenes species were included for comparison.

\section{MATERIALS AND METHODS}

Bacterial strains and growth conditions. All of the strains studied and their sources are listed in Table 1 . The majority of these strains are reference strains which were included in several polyphasic taxonomic studies $(9,18,20,21)$. Five $B$. pertussis isolates from a recent outbreak in Cincinnati, Ohio (3) (isolates kindly provided by S. Reising, Children's Hospital Medical Center, Cincinnati, Ohio), and eight sporadic $B$. pertussis isolates were included. Sporadic isolates of $B$. parapertussis, $B$. bronchiseptica, and $B$. avium were also included. The $B$. bronchiseptica and $B$. avium strains were from a wide diversity of hosts; the $B$. bronchiseptica hosts included humans (4 strains), dogs ( 2 strains), a ferret, a guinea pig, a turkey, and a rabbit, and the $B$. avium hosts included turkeys (12 strains isolated in five countries), chickens (6 strains), and a duck.

Bacteriological purity was checked by plating the organisms and examining

* Corresponding author. Mailing address: Laboratorium voor Microbiologie, Ledeganckstraat 35, B-9000 Ghent, Belgium. Phone: (32) 9 26451 13. Fax: (32)9 26450 92. E-mail: Peter.Vandamme@rug.ac.be. living cells by phase-contrast microscopy and Gram-stained cells. B. pertussis strains were grown on charcoal agar (Oxoid, Basingstoke, United Kingdom) supplemented with $10 \%$ horse blood. All other strains were grown on Trypticase soy agar (BBL, Becton Dickinson Microbiology Systems, Cockeysville, Md.) and were incubated aerobically at 36 to $37^{\circ} \mathrm{C}$.

Preparation of DNA. Extraction of DNA for PCR analysis was performed as described by Pitcher et al. (16) or by a slightly modified procedure, as described previously (8).

Thermocycler. A Perkin-Elmer model 9600 thermocycler was used for all PCR.

Amplified rDNA restriction analysis (ARDRA). Amplification of the $16 S$ rRNA genes, restriction digestion of the amplified 16S ribosomal DNA (rDNA) with the enzymes HaeIII (Boehringer, Mannheim, Germany), HhaI (Pharmacia, Biotech Benelux, Roosendaal, The Netherlands), AluI (Pharmacia), TaqI, and $B s t$ UI (New England Biolabs; purchased from Westburg, Leusden, The Netherlands), and agarose gel electrophoresis were performed as described previously (8).

The gels were scanned under UV illumination with a Foto/Analyst Visionary digital documentation system (Fotodyne, Hartland, Wis.) and were digitized with an IRIS video digitizer card and Colorvision software (Inside Technology, Amersfoort, The Netherlands). An AluI (Pharmacia) digest of plasmid pBR322 and a 128-bp fragment amplified from plasmid pGEM11Zf with phage promote T7 and SP6 were used as normalization references (8). For each strain, the normalized restriction patterns obtained with the five restriction enzymes were assembled one after the other in the order HaeIII-HhaI-AluI-TaqI-Bst UI into a combined profile and were analyzed by using the Dice similarity coefficient and the unweighted pair group with mathematical average clustering algorithm.

Randomly and repetitive element-primed PCR. DNA was amplified by using 10 random primers (five 17-mers [primers D9355, D14216, D11344, D8635, and D14307] and five 10-mers [primers 1254, 1247, 1281, 1283, and 1290]) (1), repetitive primers ERIC1R and ERIC2, and the primer pair ERIC1R-ERIC2 (22). Each PCR was performed in a $100-\mu 1$ mixture containing $50 \mathrm{mM} \mathrm{KCl}, 10$ $\mathrm{mM}$ Tris- $\mathrm{HCl}(\mathrm{pH} 9.0$ ), $2.5 \mathrm{mM} \mathrm{MgCl}, 0.1 \%$ (vol/vol) Triton X-100, $0.01 \%$ (wt/vol) gelatin, each deoxynucleoside triphosphate at a concentration of 0.2 $\mathrm{mM}, 50$ or $100 \mathrm{pmol}$ of primer, $0.6 \mathrm{U}$ of Goldstar polymerase (Eurogentec Seraing, Belgium), and $100 \mathrm{ng}$ of template DNA. The thermal cycling conditions used for the random primers were the conditions described by Akopyanz et al. (1); the thermal cycling conditions used for primers ERIC1R and ERIC2 have been described previously (19).

The gels were scanned under UV illumination, visualized, and digitized with the Gel Doc 1000 documentation system (Bio-Rad Laboratories, Nazareth, Belgium). The DNA band pattern of Enterococcus faecium LAB 1265 generated with random primer D14307 was included on each gel as a standard for normalization. The Pearson product moment correlation coefficient was used to calculate similarity values, and a cluster analysis was performed by using the unweighted pair group with mathematical average clustering algorithm.

Pattern analysis. Conversion, normalization, and numerical analysis of the DNA band patterns were performed with the GelCompar software package (Applied Maths, Kortrijk, Belgium). 
TABLE 1. Strains examined

\begin{tabular}{|c|c|c|}
\hline Strain $^{a}$ & Other designation $^{a}$ & Source $^{b}$ \\
\hline Alcaligenes denitrificans LMG $1231^{\mathrm{T}}$ & ATCC $15173^{\mathrm{T}}$ & Soil \\
\hline Alcaligenes denitrificans LMG 1860 & CIP 60.83 & Urine (France) \\
\hline Alcaligenes faecalis LMG $1229^{\mathrm{T}}$ & NCIB $8156^{\mathrm{T}}$ & \\
\hline Alcaligenes faecalis LMG 1230 & CCEB 554 & Feces (Czechoslovakia) \\
\hline Alcaligenes piechaudii LMG 1861 & NCMB 1051 & Soil \\
\hline Alcaligenes piechaudii LMG $1873^{\mathrm{T}}$ & CIP $60.75^{\mathrm{T}}$ & Pharynx \\
\hline Alcaligenes xylosoxidans LMG $1863^{\mathrm{T}}$ & ATCC $27061^{T}$ & Human, ear discharge (Japan) \\
\hline Alcaligenes xylosoxidans LMG 1866 & ATCC 15749 & Soil \\
\hline Bordetella avium LMG 1851 & $363-78$ & Turkey coryza, respiratory tract (Germany) \\
\hline Bordetella avium LMG $1852^{\mathrm{T}}$ & $591-77^{\mathrm{T}}$ & Turkey, air sac (Germany) \\
\hline Bordetella avium LMG 1854 & P-4085 & Turkey (United States) \\
\hline Bordetella avium LMG 1855 & XX14 & Turkey (Spain) \\
\hline Bordetella avium LMG 1858 & $\mathrm{NC}$ & Turkey (United States) \\
\hline Bordetella avium LMG 3524 & $946-77$ & Turkey, lung (Germany) \\
\hline Bordetella avium LMG 3549 & $2-81$ & Turkey (United Kingdom) \\
\hline Bordetella avium LMG 3550 & $3-81$ & Turkey (United Kingdom) \\
\hline Bordetella avium LMG 3557 & $298-81$ & Duck, trachea (Germany) \\
\hline Bordetella avium LMG 3559 & 897 & Turkey (Israel) \\
\hline Bordetella avium LMG 3560 & 1106 & Turkey (Israel) \\
\hline Bordetella avium LMG 3561 & XX15 & Turkey (Spain) \\
\hline Bordetella avium LMG 10973 & 15 & Broiler, trachea (Belgium, 1989) \\
\hline Bordetella avium LMG 10974 & 16 & Chicken (Belgium) \\
\hline Bordetella avium LMG 10975 & 17 & Broiler, trachea (Belgium, 1988) \\
\hline Bordetella avium LMG 10976 & 18 & Chicken, spleen (Belgium, 1989) \\
\hline Bordetella avium LMG 10977 & 19 & Broiler, trachea (Belgium, 1988) \\
\hline Bordetella avium LMG 10978 & 20 & Broiler, trachea (Belgium, 1988) \\
\hline Bordetella bronchiseptica LMG $1232^{\mathrm{T}}$ & NCTC $452^{\mathrm{T}}$ & Dog, lung (before 1932) \\
\hline Bordetella bronchiseptica LMG 1807 & NCTC 455 & Ferret, trachea (1913) \\
\hline Bordetella bronchiseptica LMG 1809 & NCTC 8751 & Guinea pig, lung (before 1951) \\
\hline Bordetella bronchiseptica LMG 1811 & NCTC 10540 & Whooping cough (United States, 1949) \\
\hline Bordetella bronchiseptica LMG 3521 & $40-81$ & Turkey, trachea (Germany, before 1981) \\
\hline Bordetella bronchiseptica LMG 3531 & NCTC 458 & Sputum (1913) \\
\hline Bordetella bronchiseptica LMG 3535 & CCM 6048 & Rabbit (before 1982) \\
\hline Bordetella bronchiseptica LMG 3538 & CCM 6155 & Dog (before 1982) \\
\hline Bordetella bronchiseptica LMG 3542 & CCUG 7865 & Whooping cough (Sweden, 1979) \\
\hline Bordetella bronchiseptica LMG 14526 & CCUG 31300 & Human, pharynx (Sweden) \\
\hline Bordetella hinzii LMG $13501^{\mathrm{T}}$ & $\mathrm{TC} 58^{\mathrm{T}}$ & Chicken, trachea (Australia) \\
\hline Bordetella hinzii LMG 14052 & TC104 & Blood culture, HIV patient ${ }^{c}$ \\
\hline Bordetella holmesii LMG $15945^{\mathrm{T}}$ & CCUG $34073^{\mathrm{T}}$ & Human, blood (United States) \\
\hline Bordetella holmesii LMG 15946 & CCUG 34074 & Human, blood (United States) \\
\hline Bordetella parapertussis LMG 1816 & NCTC 7385 & Before 1949 \\
\hline Bordetella parapertussis LMG 1818 & NCTC 10853 & Whooping cough (before 1973) \\
\hline Bordetella parapertussis LMG 1819 & CNCTC Hpp 5/59 & Whooping cough (before 1979) \\
\hline Bordetella parapertussis LMG 1820 & NCTC 10520 & Whooping cough (before 1968) \\
\hline Bordetella parapertussis LMG 1825 & NCTC 10525 & Whooping cough (before 1961) \\
\hline Bordetella parapertussis LMG 1827 & CNCTC Hpp $1 / 58$ & Whooping cough (before 1982) \\
\hline Bordetella parapertussis LMG 1833 & NCTC 8250 & Whooping cough (before 1953) \\
\hline Bordetella parapertussis LMG $14449^{\mathrm{T}}$ & CCUG $413^{\mathrm{T}}$ & Whooping cough (before 1940) \\
\hline Bordetella parapertussis LMG 14450 & CCUG $882 \mathrm{~A}$ & Whooping cough (before 1949) \\
\hline Bordetella parapertussis LMG 14451 & CCUG 4099 & Whooping cough (Sweden, 1974) \\
\hline Bordetella pertussis LMG 14452 & CCUG 699 & Sweden, 1970 \\
\hline Bordetella pertussis LMG 14453 & CCUG 9818 & Sweden, 1980 \\
\hline Bordetella pertussis LMG 14454 & CCUG 17283 & Whooping cough (before 1982) \\
\hline Bordetella pertussis LMG $14455^{\mathrm{T}}$ & CCUG $30873^{\mathrm{T}}$ & Whooping cough (before 1947) \\
\hline Bordetella pertussis LMG 14522 & CCUG 32523 & Human (Sweden, 1994) \\
\hline Bordetella pertussis LMG 15140 & CCUG 13475 & Whooping cough (before 1984) \\
\hline Bordetella pertussis LMG 15141 & CCUG 15610 & Whooping cough (before 1984) \\
\hline Bordetella pertussis LMG 15142 & CCUG 23702 & Whooping cough (Sweden, 1988) \\
\hline Bordetella pertussis LMG 15585 & CHMC 237-731 & Whooping cough (United States) \\
\hline Bordetella pertussis LMG 15586 & CHMC 212-422 & Whooping cough (United States) \\
\hline Bordetella pertussis LMG 15587 & CHMC 266-1003 & Whooping cough (United States) \\
\hline Bordetella pertussis LMG 15588 & CHMC 221-1047 & Whooping cough (United States) \\
\hline Bordetella pertussis LMG 15589 & CHMC 244-889 & Whooping cough (United States) \\
\hline Bordetella trematum LMG $13506^{\mathrm{T}}$ & $1779^{\mathrm{T}}$ & Human, chronic otitis media (Germany) \\
\hline Bordetella trematum LMG 14446 & CCUG 13902 & Leg wound (1980) \\
\hline
\end{tabular}

a ATCC, American Type Culture Collection, Rockville, Md.; CCEB, Culture Collection of Entomogenous Bacteria, Department of Insect Pathology, Institute of Entomology, Prague, Czech Republic; CCM, Czech Collection of Microorganisms, Brno, Czech Republic; CCUG, Culture Collection, Department of Clinical Bacteriology, University of Göteborg, Göteborg, Sweden; CIP, Collection bactérienne de l'Institut Pasteur, Paris, France; CNCTC, Czechoslovak National Collection of Type Cultures, Institute of Hygiene and Epidemiology, Prague, Czech Republic; LMG, Laboratorium voor Microbiologie Gent Culture Collection, Universiteit Gent, Ghent, Belgium; NCIB, National Collection of Industrial Bacteria, NCIMB, Ltd., Aberdeen, Scotland, United Kingdom; NCTC, National Collection of Type Cultures, Central Public Health Laboratory, London, United Kingdom; CHMC, Children's Hospital Medical Center, Cincinnati, Ohio.

${ }^{b}$ If known.

${ }^{c}$ HIV, human immunodeficiency virus. 


\section{RESULTS}

Reproducibility. In general, the level of reproducibility for computer-assisted comparisons of combined ARDRA patterns obtained on different gels was at least $95 \%$. Occasional low values were due to electrophoretic anomalies, and these data were not used in the numerical analysis.

For randomly and repetitive element-primed PCR, reproducibility values greater than $92 \%$ were obtained for patterns generated with a single batch of reagents. The use of another brand of DNA polymerase introduced considerable differences in at least some of the patterns. We therefore compared only data which were generated with the same batches of reagents.

ARDRA. In the numerical analysis of the combined ARDRA patterns (Fig. 1), B. pertussis, B. parapertussis, and B. bronchiseptica strains formed a single cluster above a similarity level of $97 \%$, which is within the reproducibility range of the method. All $B$. avium strains clustered together above a similarity level of $98 \%$. The Alcaligenes xylosoxidans and Alcaligenes denitrificans strains (20) formed a single cluster at a similarity level of 97\%. The combined ARDRA patterns of B. avium, Bordetella hinzil, and Bordetella trematum were very similar and clustered together at a similarity level of $92 \%$. Alcaligenes piechaudii, Bordetella holmesii, and Alcaligenes faecalis occupied clearly distinct positions on the dendrogram, and the latter organism was the most remote member of the group.

Although the combined pattern analysis in which five restriction enzymes were used revealed high overall levels of similarity between $A$. xylosoxidans and $A$. denitrificans and among $B$. avium, $B$. hinzii, and $B$. trematum, the patterns generated with individual enzymes allowed us to differentiate each of these species. For instance, the HaeIII digests of $A$. denitrificans and A. xylosoxidans strains resulted in clear differentiation on the basis of an additional DNA band (approximate molecular weight, $785 \mathrm{bp}$ ) present in the patterns of strains of the former species (Fig. 2). Similarly, AluI digests generated different band patterns for B. avium, B. hinzii, and B. trematum strains (Fig. 2). For rapid identification purposes, digestion of the amplicon with $A l u \mathrm{I}$ followed by digestion with HaeIII (for differentiation of $A$. denitrificans, $A$. xylosoxidans, and $B$. hinzii) or $H$ haI (for differentiation of $A$. piechaudii and $B$. avium) could be used to differentiate all of the species (Fig. 2).

Randomly and repetitive element-primed PCR. The suitability of all primers for generating DNA band patterns was evaluated by using a minimal set of strains representing various species. Especially the primer pair ERIC1R-ERIC2 and primers ERIC2, D8635, D9355, and D11344 generated high levels of pattern diversity. The band patterns generated by the other primers were less useful or not useful for at least some of the strains examined. All of the isolates were subsequently characterized by using random primer D8635 and the repetitive primer pair ERIC1R-ERIC2.

With both of the primers examined, some variability was detected among the $B$. avium strains, but the overall DNA amplification patterns were similar and were distinct from the patterns of the other species examined. Comparable variability was found among the $B$. bronchiseptica strains (Fig. 3). $B$. pertussis and $B$. parapertussis strains, however, were each characterized by a single invariable DNA amplification pattern which was similar to the patterns of $B$. bronchiseptica strains (some patterns illustrating the diversity of the DNA amplification patterns are shown in Fig. 3).

Very different DNA amplification patterns were generated when we examined strains belonging to other species, but the numbers of strains included per taxon were too small to con- clude whether the DNA amplification patterns were species specific (data not shown).

$B$. pertussis strains were further analyzed by using the remaining 11 primers. Except for strain LMG $14455^{\mathrm{T}}$, no differences were detected. Strain LMG $14455^{\mathrm{T}}$ had a slightly aberrant DNA amplification pattern with some of the primers examined (D9355, D14216, D11344, D14307, and ERIC2).

\section{DISCUSSION}

The classification of $B$. pertussis, B. parapertussis, and $B$. bronchiseptica as distinct species is controversial, and the relationship of these taxa is a taxonomic curiosity. As discussed previously, high levels of DNA-DNA binding suggest that all three organisms belong to a single species, but this suggestion is contradicted by the high degree of heterogeneity in their phenotypes $(11,18,21,24)$.

A variety of DNA-based typing methods have been developed during the last decade, and each has its own range of applications. A number of these methods have been shown to be useful for discriminating strains at various taxonomic levels. It was our aim in the present study to compare the genotypic diversity of strains of $B$. pertussis, $B$. parapertussis, and $B$. bronchiseptica by using different genome-oriented typing methods and to compare the observed heterogeneity with the heterogeneity detected in B. avium. The latter species is genotypically and phenotypically homogeneous and differs both in genotype and in phenotype from related Bordetella and Alcaligenes species $(9,20,21,24)$.

ARDRA. Amplification and digestion of rDNA have been used for identifying and typing a wide variety of bacteria $(7,8)$. Methodological variability can be introduced by the amplified region selected (16S rDNA, 23S rDNA, and/or spacer region), which has a major impact on the resolution and hence the discriminatory power of the technique. In the present study, the target for the PCR was the almost complete 16S rRNA gene without spacer sequences. This approach has been shown to be useful primarily for species level identification, but not for infraspecific typing $(7,8)$. ARDRA patterns obtained with five different restriction enzymes were combined, and a numerical comparison was performed by using these combined patterns (Fig. 1). Although the patterns generated by individual enzymes were often useful for differentiating some species, they were never useful for differentiating all of the species. This is illustrated in Fig. 2, in which $A l u$ I digests differentiated $B$. holmesii and $B$. trematum, but not $B$. avium and $A$. piechaudii or $A$. denitrificans, $A$. xylosoxidans, and $B$. hinzii. Conversely, numerical analysis of the combined patterns allowed us to distinguish each individual species except $B$. pertussis, $B$. parapertussis, and $B$. bronchiseptica, which formed a single homogeneous cluster (Fig. 1). These data indicate that numerical analysis of combined ARDRA patterns is an excellent tool for differentiating species within the family Alcaligenaceae and further support the genotypic evidence which indicates that $B$. pertussis, $B$. parapertussis, and $B$. bronchiseptica form a single species. The failure to differentiate the latter three species by this approach is not unexpected given the high levels of $16 \mathrm{~S}$ rDNA sequence similarity (more than $99.7 \%$ ) between the type strains of these species (24).

Randomly and repetitive element-primed PCR typing. Typing methods based on the amplification of DNA fragments in which random sequences are used as primers in the PCR have been referred to as DNA amplification fingerprinting, arbitrarily primed PCR, or randomly amplified polymorphic DNA analysis $(2,23,25)$. Likewise, oligonucleotides complementary to fragments of repetitive elements (repetitive extragenic pal- 




FIG. 1. Dendrogram derived from unweighed pair group average linkage of Dice similarity coefficients for the combined ARDRA patterns of all of the strains studied. Pseudomonas fluorescens LMG 1799 was used as an outgroup reference strain. 


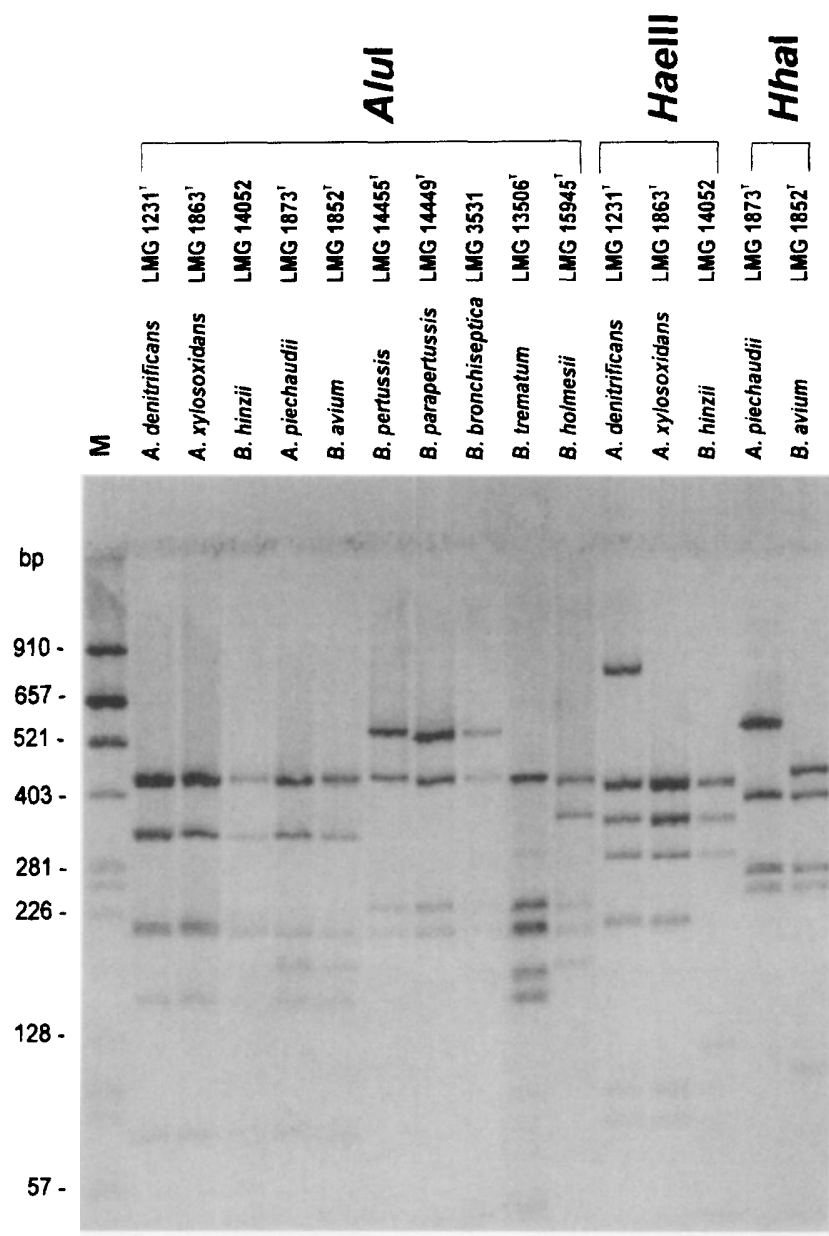

FIG. 2. Normalized computer profiles of the ARDRA patterns of a selection of the strains obtained with different restriction enzymes. Lane $M$ contained the molecular weight marker.

indromic and enterobacterial repetitive intergenic consensus motifs) have also been used as primers in PCR assays (12). Although primarily used for strain differentiation, these PCRbased typing methods have proved to be useful for identification of species belonging to several genera, including the genera Campylobacter, Capnocytophaga, and Enterococcus $(4,6)$.

In the present study, several primers were useful for differentiating a selection of strains representing various species in the family Alcaligenaceae. Two of these primers were selected to examine all of the isolates, and this analysis revealed the presence of different types among the B. avium strains (Fig. 3). A comparable heterogeneity was found among the $B$. bronchiseptica strains, but was absent in B. pertussis and B. parapertussis strains. For each of the latter two species, only a single pattern was generated with the primer pair ERIC1R-ERIC2 and primer D8635. When $B$. pertussis strains were examined with additional primers, only the type strain occasionally differed from the other strains. This aberrant nature of the $B$. pertussis type strain was also demonstrated by whole-cell protein electrophoresis (18). These data indicate that random and repetitive element-based PCR typing can be useful for epidemiological investigations of $B$. bronchiseptica and $B$. avium strains. However, these methods failed to identify a reasonable number of infraspecific types within $B$. pertussis and $B$. parapertussis and therefore seem inadequate for epidemiological
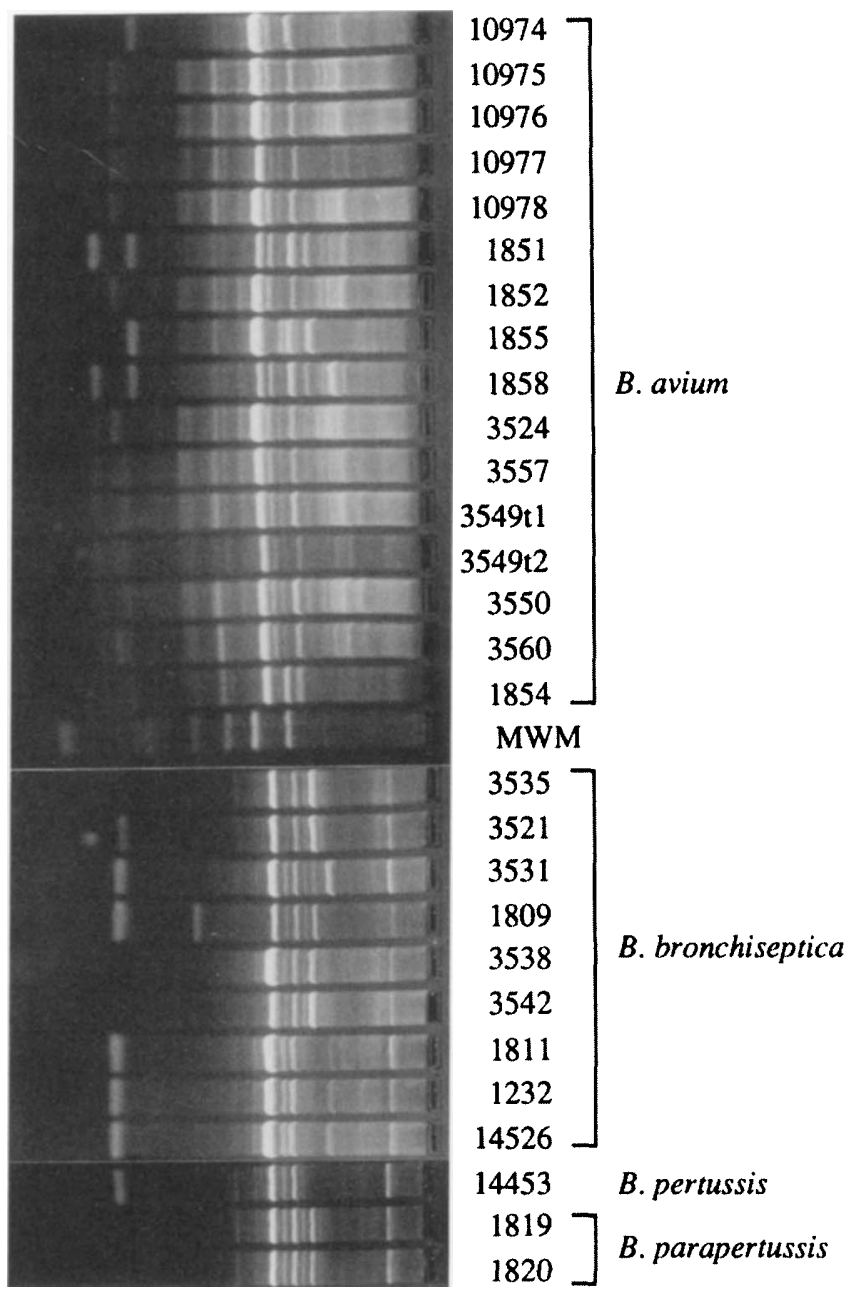

FIG. 3. DNA amplification patterns of a selection of Bordetella strains generated by ERIC1R-ERIC2-primed PCR. The molecular weight marker used (lane MWM) comprised DNA bands at (from right to left) $910,657,521,403$, $281,226,128$, and $57 \mathrm{bp}$.

studies of these species. DNA band patterns generated by these techniques were clearly useful for differentiating $B$. avium strains from strains belonging to the $B$. bronchiseptica group (including $B$. pertussis and $B$. parapertussis) or other Bordetella or Alcaligenes species. The observed diversity in the reference strains of the remaining species studied did not allow us to draw conclusions concerning the general suitability of the method for species differentiation within the entire family $\mathrm{Al}$ caligenaceae (data not shown).

In conclusion, our data substantiate the conclusion that there is little genotypic evidence which justifies the present species status of $B$. pertussis, $B$. parapertussis, and $B$. bronchiseptica. Strains of these three species, which together were referred to as the $B$. bronchiseptica group, behave as a single species comparable to strains of $B$. avium. The methods which we used did not allow us to identify strains of the $B$. bronchiseptica group at the species level, but clearly separated strains of the $B$. bronchiseptica group from $B$. avium strains, and the ARDRA results could be used to differentiate all or most other members of the family Alcaligenaceae (Fig. 1). In contrast to macrorestriction enzyme analysis (10), none of the techniques used in this study readily allowed us to differentiate sporadic isolates of $B$. pertussis and $B$. parapertussis. Our data therefore 
suggest that there is considerably less genotypic variability in $B$. pertussis and $B$. parapertussis than in $B$. bronchiseptica and $B$. avium. The results of examinations of large numbers of strains by multilocus enzyme electrophoresis suggest that the $B$. bronchiseptica group can be subdivided on the basis of host specificity, with $B$. pertussis, $B$. parapertussis, and the porcine $B$. bronchiseptica isolates as major lineages (5) (B. bronchiseptica strains from other sources represent additional lineages $[5,14$, 15]). The DNA fingerprints generated by ERIC1R-ERIC2and D8635-primed PCR support this hypothesis.

\section{ACKNOWLEDGMENTS}

P.V., M.H., and P.D. are indebted to the Fund for Scientific Research - Flanders (Belgium) for positions as postdoctoral fellows (P.V. and M.H.) and a senior research associate (P.D.). K.K. is indebted to the Fund for Medical Scientific Research, Belgium, for research and personnel grants. Part of this research was performed in the framework of contract G. O. A. 91/96-2 with the Ministerie van de Vlaamse Gemeenschap, Bestuur Wetenschappelijk Onderzoek (Belgium).

We thank all depositors of strains listed in Table 1.

\section{REFERENCES}

1. Akopyanz, N., N. O. Bukanov, T. U. Westblom, S. Kresovich, and D. E. Berg. 1992. DNA diversity among clinical isolates of Helicobacter pylori detected by PCR-based RAPD fingerprinting. Nucleic Acids Res. 20:5137-5142.

2. Caetano-Anolles, G., B. J. Bassam, and P. M. Gresshoff. 1991. DNA amplification fingerprinting using very short arbitrary oligonucleotide primers Bio/Technology 9:553-556.

3. Christie, D. C., M. L. Marx, C. D. Marchant, and S. F. Reising. 1995. The 1993 epidemic of pertussis in Cincinnati: resurgence of disease in a highly immunized population of children. N. Engl. J. Med. 331:16-21.

4. Descheemaeker, P., C. Lammens, B. Pot, P. Vandamme, and H. Goossens. 1997. Evaluation of arbitrarily primed PCR analysis and genome macrorestriction profiling for the differentiation of enterococci important in human medicine. Int. J. Syst. Bacteriol. 47:555-567.

5. Giardina, P. C., L.-A. Foster, J. M. Musser, B. J. Akerley, J. F. Miller, and D. W. Dyer. 1995. bvg repression of alcaligin synthesis in Bordetella bronchiseptica is associated with phylogenetic lineage. J. Bacteriol. 177:6058-6063.

6. Giesendorf, B. A. J., W. G. V. Quint, P. Vandamme, and A. van Belkum. 1996. Generation of DNA probes for detection of microorganisms by polymerase chain reaction fingerprinting. Zentralbl. Bakteriol. Parasitenkd. Infektionskr. Hyg. Abt. 1 Orig. 283:417-430.

7. Gürtler, V., and V. A. Stanisich. 1996. New approaches to typing and identification of bacteria using the $16 \mathrm{~S}-23 \mathrm{~S}$ rDNA spacer region. Microbiology 142:3-16.

8. Heyndrickx, M., L. Vauterin, P. Vandamme, K. Kersters, and P. De Vos. 1996. Applicability of combined amplified ribosomal DNA restriction analysis (ARDRA) patterns in bacterial phylogeny and taxonomy. J. Microbiol. Methods 26:247-259.

9. Kersters, K., K.-H. Hinz, A. Hertle, P. Segers, A. Lievens, O. Siegmann, and
J. De Ley. 1984. Bordetella avium sp. nov., isolated from the respiratory tracts of turkeys and other birds. Int. J. Syst. Bacteriol. 34:56-70.

10. Khattak, M. N., and R. C. Matthews. 1993. Genetic relatedness of Bordetella species as determined by macrorestriction digests resolved by pulsed-field gel electrophoresis. Int. J. Syst. Bacteriol. 43:659-664.

11. Kloos, W. E., N. Mohapatra, W. Dobrogosz, J. W. Ezzell, and C. R. Manclark. 1981. Deoxyribonucleotide sequence relationships among Bordetella species. Int. J. Syst. Bacteriol. 31:173-176.

12. Lupski, J. R., and G. E. Weinstock. 1992. Short, interspersed repetitive DNA sequences in prokaryotic genomes. J. Bacteriol. 174:4525-4529.

13. Maslow, J. N., M. E. Mulligan, and R. D. Arbeit. 1993. Molecular epidemiology: application of contemporary techniques to the typing of microorganisms. Clin. Infect. Dis. 17:153-164.

14. Musser, J. M., D. A. Bemis, H. Ishikawa, and R. K. Selander. 1987. Clonal diversity and host distribution in Bordetella bronchiseptica. J. Bacteriol. 169: 2793-2803.

15. Musser, J. M., E. L. Hewlett, M. S. Peppler, and R. K. Selander. 1986. Genetic diversity and relationships in populations of Bordetella spp. J. Bacteriol. 166:230-237.

16. Pitcher, D. G., N. A. Saunders, and R. J. Owen. 1989. Rapid extraction of bacterial genomic DNA with guanidium thiocyanate. Lett. Appl. Microbiol. 8:151-156.

17. Tenover, F. C., R. D. Arbeit, R. V. Goering, P. A. Mickelsen, B. E. Murray, D. H. Persing, and B. Swaminathan. 1995. Interpreting chromosomal DNA restriction patterns produced by pulsed-field gel electrophoresis: criteria for bacterial strain typing. J. Clin. Microbiol. 33:2233-2239.

18. Vancanneyt, M., P. Vandamme, and K. Kersters. 1995. Differentiation of Bordetella pertussis, B. parapertussis, and B. bronchiseptica by whole-cell protein electrophoresis and fatty acid analysis. Int. J. Syst. Bacteriol. 45:843-847.

19. Vandamme, P., B. A. J. Giesendorf, A. van Belkum, D. Pierard, S. Lauwers, K. Kersters, J.-P. Butzler, H. Goossens, and W. G. V. Quint. 1993. Discrimination of epidemic and sporadic isolates of Arcobacter butzleri by polymerase chain reaction-mediated DNA fingerprinting. J. Clin. Microbiol. 31 $3317-3319$.

20. Vandamme, P., M. Heyndrickx, M. Vancanneyt, B. Hoste, P. De Vos, E. Falsen, K. Kersters, and K.-H. Hinz. 1996. Bordetella trematum sp. nov., isolated from wounds and ear infections in humans, and reassessment of Alcaligenes denitrificans Rüger and Tan 1983. Int. J. Syst. Bacteriol. 46:849858

21. Vandamme, P., J. Hommez, M. Vancanneyt, M. Monsieurs, B. Hoste, B. Cookson, C. H. Wirsing von Konig, K. Kersters, and P. Blackall. 1995. Bordetella hinzii sp. nov., isolated from poultry and humans. Int. J. Syst. Bacteriol. 45:37-45.

22. Versalovic, J. T. Koeuth, and J. R. Lupski. 1991. Distribution of repetitive DNA sequences in eubacteria and application to fingerprinting of bacterial genomes. Nucleic Acids Res. 19:6823-6831.

23. Welsh, J., and M. McClelland. 1990. Fingerprinting genomes using PCR with arbitrary primers. Nucleic Acids Res. 18:7213 7218

24. Weyant, R. S., D. G. Hollis, R. E. Weaver, M. F. M. Amin, A. G. Steigerwalt, S. P. O'Connor, A. M. Whitney, M. I. Daneshvar, C. W. Moss, and D. J. Brenner. 1995. Bordetella holmesii sp. nov., a new gram-negative species associated with septicemia. J. Clin. Microbiol. 33:1-7.

25. Williams, J. G. K., A. R. Kubelic, K. J. Livak, J. A. Rafalski, and S. V. Tingey, 1990. DNA polymorphisms amplified by arbitrary primers are useful as genetic markers. Nucleic Acids Res. 18:6531-6535. 